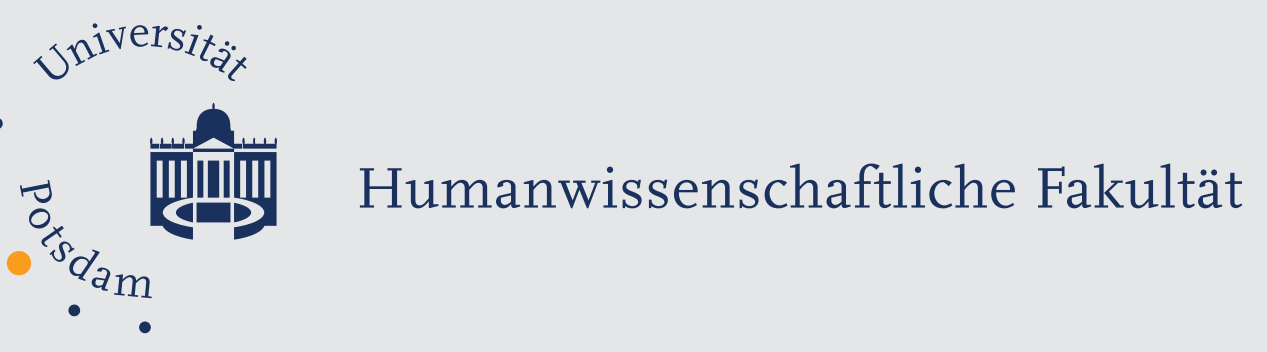

Anja Carlsohn | Friederike Scharhag-Rosenberger | Michael Cassel Frank Mayer

\title{
Resting Metabolic Rate in Elite Rowers and Canoeists: Difference between Indirect Calorimetry and Prediction
}

Suggested citation referring to the original publication:

Annals of nutrition \& metabolism 58(3) (2011), pp. 239-244

DOI http://dx.doi.org/10.1159/000330119

ISSN (print) 0250-6807

ISSN (online) 1421-9697

Postprint archived at the Institutional Repository of the Potsdam University in:

Postprints der Universität Potsdam

Humanwissenschaftliche Reihe ; 329

ISSN 1866-8364

http://nbn-resolving.de/urn:nbn:de:kobv:517-opus4-399837 



\title{
Resting Metabolic Rate in Elite Rowers and Canoeists: Difference between Indirect Calorimetry and Prediction
}

\author{
Anja Carlsohn Friederike Scharhag-Rosenberger Michael Cassel Frank Mayer \\ University Outpatient Clinic Potsdam, Sports Medicine and Sports Orthopaedics, University of Potsdam, \\ Potsdam, Germany
}

\section{Key Words}

Energy requirement $\cdot$ Calorimetry $\cdot$ Fat-free mass ·

Nutritional counseling $\cdot$ Athletes

\begin{abstract}
Background: Athletes may differ in their resting metabolic rate (RMR) from the general population. However, to estimate the RMR in athletes, prediction equations that have not been validated in athletes are often used. The purpose of this study was therefore to verify the applicability of commonly used RMR predictions for use in athletes. Methods: The RMR was measured by indirect calorimetry in 17 highly trained rowers and canoeists of the German national teams (BMI 24 $\pm 2 \mathrm{~kg} / \mathrm{m}^{2}$, fat-free mass $69 \pm 15 \mathrm{~kg}$ ). In addition, the RMR was predicted using Cunningham (CUN) and Harris-Benedict (HB) equations. A two-way repeated measures ANOVA was calculated to test for differences between predicted and measured RMR $(\alpha=0.05)$. The root mean square percentage error (RMSPE) was calculated and the Bland-Altman procedure was used to quantify the bias for each prediction. $\boldsymbol{R e}$ sults: Prediction equations significantly underestimated the RMR in males $(p<0.001)$. The RMSPE was calculated to be $18.4 \%$ (CUN) and $20.9 \%$ (HB) in the entire group. The bias was $133 \mathrm{kcal} / 24 \mathrm{~h}$ for CUN and $202 \mathrm{kcal} / 24 \mathrm{~h}$ for HB. Conclusions:
\end{abstract}

Predictions significantly underestimate the RMR in male heavyweight endurance athletes but not in females. In athletes with a high fat-free mass, prediction equations might therefore not be applicable to estimate energy requirements. Instead, measurement of the resting energy expenditure or specific prediction equations might be needed for the individual heavyweight athlete.

Copyright $\odot 2011$ S. Karger AG, Basel

\section{Introduction}

To estimate the energy demands of an individual, knowledge of physical activity-related energy expenditure and the individual's resting metabolic rate (RMR) is required. While physical activity-related energy expenditure is the most variable factor of total energy expenditure, the RMR is its largest component [1]. To estimate the RMR, several different prediction equations have been developed [2]. However, there is no standard prediction equation that fits all individuals, and the characteristics of a population need to be considered [3, 4].

One characteristic affecting energy expenditure is the fat-free mass (FFM), which accounts for about $50-80 \%$ of the individual variability in RMR $[1,5]$. However, RMR in

\section{KARGER}

Fax +41613061234

E-Mail karger@karger.ch

www.karger.com
(C) 2011 S. Karger AG, Basel

0250-6807/11/0583-0239\$38.00/0

Accessible online at:

www.karger.com/anm
Anja Carlsohn, $\mathrm{PhD}$

University Outpatient Clinic Potsdam, Am Neuen Palais 10

DE-14469 Potsdam (Germany)

Tel. +493319771768

E-Mail carlsohn@uni-potsdam.de 
individuals of the same FFM may vary by approximately $3 \mathrm{MJ} /$ day (about $715 \mathrm{kcal} / 24 \mathrm{~h}$ ), which suggests that additional components substantially influence the RMR [6]. For example, Illner et al. [7] reported that metabolically active organs contribute considerably to the RMR. In addition, the RMR might be influenced by exercise-induced activation of the sympathetic nervous system [8]. Thus, besides chronic, exercise-induced changes in body composition, the RMR might be modulated by regular physical activity itself [1]. Currently, prediction equations developed by Cunningham [9] and Harris and Benedict [10] are recommended by the American College of Sports Medicine (ACSM) to estimate the RMR in athletes [11]. Cunningham's prediction model (CUN) comprises FFM; thus, differences in body composition between athletes and nonathletes are considered. In contrast, the prediction equations by Harris and Benedict (HB) do not include FFM, but do include total body weight and gender. As shown by Thompson and Manore [12], the Cunningham equation is highly accurate in endurance athletes. However, anthropometric data such as height, weight, and FFM may considerably differ in elite athletes, depending on the kind of sport [13], and thus affect the applicability of commonly used RMR prediction equations. For example, elite heavyweight rowers have been shown to have a significantly larger total body mass and FFM compared to nonathletes [14]. Neither HB nor CUN were developed for the athletic population; rather, they were developed in healthy untrained subjects $(C U N, n=223)$ and adults and a small number of infants ( $\mathrm{HB}, \mathrm{n}=241$ ). In addition, $\mathrm{HB}$ and CUN were developed in 1918 and 1980, respectively $[9,15]$. In the meantime, many prediction equations have become available, and some of them might be regarded as more appropriate. For example, de Lorenzo et al. [16] have established an RMR prediction equation for male athletes. Nevertheless, ACSM recommends the Harris-Benedict or Cunningham equation, though they have not been developed for the athletic population and the accuracy of RMR prediction models has not been tested in this specific athletic population with a very high FFM. Thus, the applicability of both the Cunningham equation and the HarrisBenedict equation in athletes with a very high FFM is questionable.

Therefore, the purpose of this study was to evaluate the applicability of commonly used RMR prediction equations in highly trained, heavyweight endurance athletes. It was hypothesized that prediction equations which do not consider body composition and were not developed for use in athletes will substantially bias the RMR in individuals with a remarkably high FFM.
Table 1. Participants' characteristics

\begin{tabular}{lcc}
\hline & Females & Males \\
\hline Age, years & $23.3 \pm 3.0$ & $23.0 \pm 5.0$ \\
Weight, kg & $69.3 \pm 11.0$ & $92.9 \pm 10.0^{*}$ \\
Height, kg & $175.0 \pm 7.0$ & $193.0 \pm 7.0^{*}$ \\
BMI & $22.5 \pm 2.0$ & $25.0 \pm 2.0$ \\
Body fat, \% & $18.5 \pm 4.0$ & $12.7 \pm 2.0$ \\
FFM, kg & $56.1 \pm 7.0$ & $81.0 \pm 8.0^{*}$ \\
Duration of training, min/day & $152.0 \pm 41.0$ & $133.0 \pm 88$ \\
VO $_{2 \text { max }}, \mathrm{ml} / \mathrm{min} / \mathrm{kg}$ & $43.0 \pm 2.5$ & $57.0 \pm 4.5$ \\
\hline
\end{tabular}

Data are presented as means $\pm \mathrm{SD}$.

* Significantly different from females.

\section{Materials and Methods}

\section{Participants}

Seventeen highly trained rowing ( 3 males and 5 females) and canoe racing ( 5 males and 4 females) athletes of the German national teams were enrolled into this study (age $23 \pm 4$ years, BMI $24 \pm 2 \mathrm{~kg} / \mathrm{m}^{2}$, FFM $72 \pm 14 \mathrm{~kg}$ ). The average number of training sessions per week was $15.9 \pm 3.6$ for males and $18.3 \pm 2.9$ for females. Detailed subjects' characteristics are shown in table 1.

Individuals who were smokers or persons diagnosed with hypo- or hyperthyroidism [17] were excluded from the study to avoid possible influences on the RMR. All participants were encouraged to keep their usual eating habits during the 2 weeks before the study. Additionally, participants were asked about weight changes during the last 2 months before the start of the study. Weight changes had to be less than $\pm 4.5 \mathrm{~kg}$ [18] to avoid effects of restrained eating $[19,20]$ or overnutrition [21] when measuring the RMR; otherwise volunteers were excluded from the study. A total of 19 athletes volunteered to participate in the study, 17 of which were finally included. All participants gave written informed consent after the study had been approved by the local ethics committee.

\section{Study Design}

The study was conducted in a cross-sectional design. Ahead of experimental procedures, inclusion criteria were verified by phone calls using a checklist. Participants visited the laboratory on two separate days. On the first day a medical check including a fasting blood sample for analysis of thyroid-stimulating hormone, ferritin, and blood counts to identify subjects with iron deficiency or endocrinal disturbances was conducted. The blood parameters of all participants were within reference values. Medical prescriptions were checked during anamnesis by a physician, and no medications that influence the RMR were reported. Six out of 8 females reported contraceptive use, which means RMR variance due to the menstrual cycle is negligible in these participants [22]. Therefore, the menstrual state of female athletes was not controlled for in measuring the RMR. To characterize the fitness level of the athletes, the maximum oxygen consumption $\left(\mathrm{VO}_{2 \max }\right)$ was measured during an incremental treadmill test as described elsewhere [23]. On the second day, the RMR was measured and anthropometric data were collected. All tests were per- 
formed within 12 weeks to avoid seasonal variance of the RMR as described by others [24].

\section{Anthropometric Measurements}

Participants arrived between 6:00 and 7:30 a.m. at the laboratory and rested for $10 \mathrm{~min}$ in a sitting position before the RMR was measured. Anthropometric measurements (body height, body weight, and skin fold thickness) were conducted in a fasted state $(\geq 12 \mathrm{~h}$ ) with the subjects wearing underwear. Skin fold thickness was measured by the same experienced examiner, and the coefficient of variance $(\mathrm{CV})$ was calculated to be $4.6 \%$ in a previous pilot study. Body fat was estimated via the 10 -site skin fold method of Parizkova and Buzkova [25] using a Lange caliper (DKSH Ltd., Zürich, Switzerland). The FFM was calculated from the whole body mass and the body fat mass.

\section{RMR Measurements}

All participants were instructed to minimize movement after awaking and before calorimetry, and they were asked to refrain from alcohol [26] or caffeine consumption [27, 28] and vigorous exercise the day before RMR measurements [1]. Low-intensity training was allowed the day before calorimetry as interruption of habitual training by cessation of exercise may substantially affect the RMR in highly trained individuals [29]. The RMR was measured the morning after a restful night's sleep in a silent room with an ambient temperature of $22-25^{\circ} \mathrm{C}$ while the participants rested in a supine position [4]. The experimental conditions were exactly standardized for each subject by means of a checklist. The gas exchange was measured for $30.9 \pm 4$ min using a face mask device (ZAN 600 CPET; nSpire Health Group, Oberthulba, Germany). Calibrations of flow and gas analyzers were performed before each measurement using a 1-liter syringe, room air $\left(20.94\right.$ vol\% $\mathrm{O}_{2}$ and $\left.0.04 \mathrm{vol} \% \mathrm{CO}_{2}\right)$, and a standard gas $\left(15.90 \pm 0.32 \mathrm{vol} \% \mathrm{O}_{2}\right.$ and 4.99 \pm 0.10 vol\% $\mathrm{CO}_{2}$; Air Liquid, Krefeld, Germany). Breath-bybreath measurements were conducted using an amperometric solid electrolyte sensor for oxygen measurement and an infrared sensor for $\mathrm{CO}_{2}$ measurements. The oxygen uptake $\left(\mathrm{VO}_{2}\right)$ and respiratory exchange ratio were analyzed within the last $20 \mathrm{~min}$ of the resting period and during a minimum of 5 consecutive minutes in steady-state conditions. Steady-state was defined as intervals where the average minute oxygen consumption $\left(\mathrm{VO}_{2}\right)$ and carbon dioxide production $\left(\mathrm{VCO}_{2}\right)$ changes by $<10 \%$ and the average respiratory exchange ratio changes by $<5 \%$ [30]. The RMR was determined using the Weir equation [31]. Using these standardized RMR measurement procedures, the CV was calculated to be $2.1 \%$ in a pilot test-retest study in our laboratory.

\section{RMR Predictions}

For each subject, the RMR was predicted using standard equations by Cunningham [9] and Harris and Benedict [10] as stated below:

$$
\begin{aligned}
& \text { Cunningham: } \\
& \operatorname{RMR}(\mathrm{kcal} / 24 \mathrm{~h})=500+22 \times \mathrm{FFM}(\mathrm{kg})
\end{aligned}
$$

Harris and Benedict:

Females: RMR $(\mathrm{kcal} / 24 \mathrm{~h})=655.96+1.850 \times \mathrm{H}(\mathrm{cm})+$ $9.563 \times \mathrm{BW}(\mathrm{kg})-4.676 \times \mathrm{A}$ (years)

Males: RMR $(\mathrm{kcal} / 24 \mathrm{~h})=66.473+5.003 \times \mathrm{H}(\mathrm{cm})+$ $13.752 \times \mathrm{BW}(\mathrm{kg})-6.755 \times \mathrm{A}$ (years),

where $\mathrm{BW}=$ body weight; $\mathrm{H}=$ height, and $\mathrm{A}=$ age.

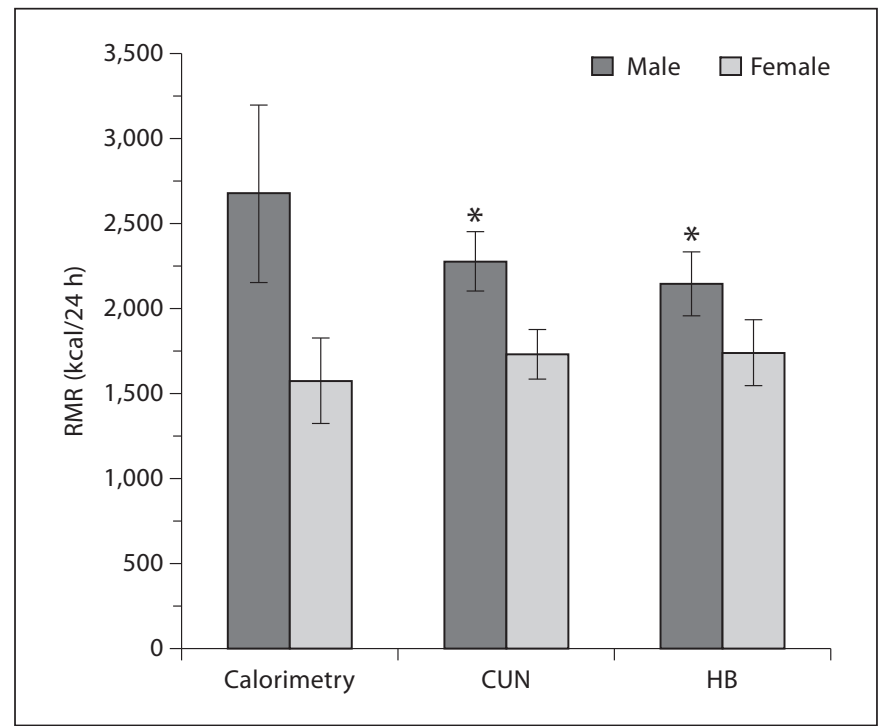

Fig. 1. Measured (calorimetry) and predicted (CUN and HB) RMR in males and females. ${ }^{*}$ Results are significantly different from calorimetry.

Data Analysis

Data were analyzed for the entire group and with respect to gender and presented as means \pm standard deviation (SD). As a normal distribution was present for all dependent variables (Shapiro-Wilk test), parametric tests were chosen. To estimate the relative difference between predicted and measured RMR, the root mean square percentage error (RMSPE) was calculated for each equation. Two-factorial ANOVA with repeated measures was used to test for statistically significant differences between predicted and measured RMR (factor 1: result of measurement or prediction; factor 2: gender). For post hoc comparisons, the Scheffé test was used. $\mathrm{p}<0.05$ for the $\alpha$-error was considered significant. The Bland-Altman procedure was used to identify the bias and to evaluate the precision of the prediction equations [32, 33]. The bias was calculated as the mean difference between a prediction equation and the measurement. The SD of the mean (the range within which $95 \%$ of the differences between the prediction and the measurement will lie) served to evaluate the precision of a prediction equation (95\% limits of agreement; LOA). A regression analysis was performed to identify a proportional bias [34].

\section{Results}

For females, the predicted RMR using either CUN $(1,734 \pm 147 \mathrm{kcal} / 24 \mathrm{~h}, \mathrm{p}=0.831)$ or $\mathrm{HB}(1,737 \pm 200$ $\mathrm{kcal} / 24 \mathrm{~h}, \mathrm{p}=0.818$ ) tended to be higher than the measured RMR $(1,577 \pm 253 \mathrm{kcal} / 24 \mathrm{~h}$ or $28.2 \pm 4.0 \mathrm{kcal} / \mathrm{kg}$ $\mathrm{FFM} / 24 \mathrm{~h}$ ) but was not statistically different from the measured RMR. In males, the predicted RMR was significantly lower for both CUN $(2,260 \pm 181 \mathrm{kcal} / 24 \mathrm{~h}$, $\mathrm{p}=0.005)$ and $\mathrm{HB}(2,133 \pm 188 \mathrm{kcal} / 24 \mathrm{~h}, \mathrm{p}<0.001) \mathrm{com}^{-}$ 
Fig. 2. Mean difference between measured and predicted RMR using the Cunningham equation.
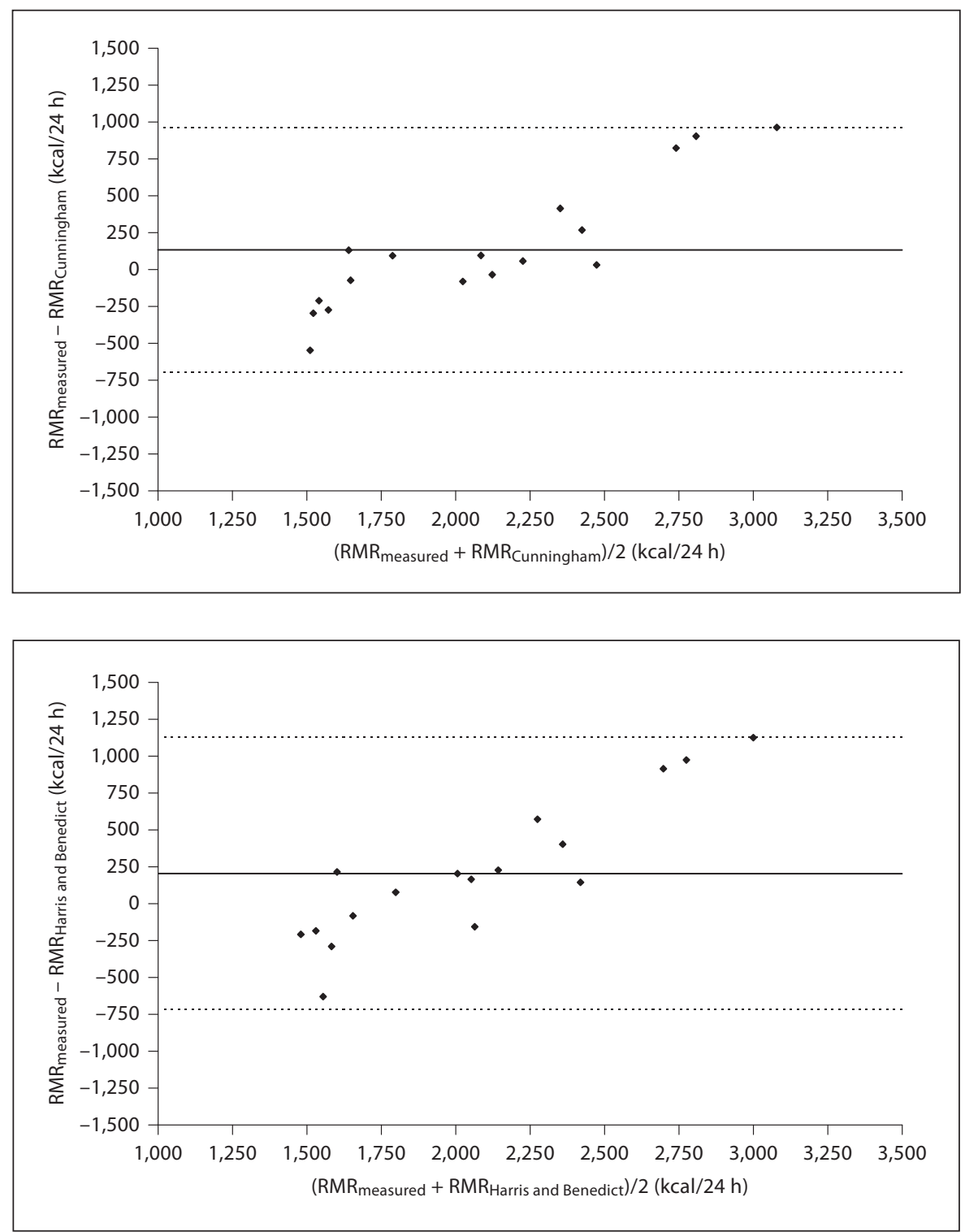

Fig. 3. Mean difference between measured and predicted RMR using the HarrisBenedict equation. ly. The mean difference between CUN and the measurements was $133 \mathrm{kcal} / 24 \mathrm{~h}$. The LOA ranged from -697 $\mathrm{kcal} / 24 \mathrm{~h}$ to $964 \mathrm{kcal} / 24 \mathrm{~h}$ (fig. 2).

\section{Harris-Benedict Equation}

Using the Harris-Benedict equation, the RMR in males was significantly underestimated $(\mathrm{p}<0.001)$. No difference between the measured and predicted RMR was observed in female athletes $(\mathrm{p}=0.559)$. The RMSPE for the entire group was $20.9 \%$, and it was $21.5 \%$ for males and $20.4 \%$ females, respectively. The bias was calculated as $202 \mathrm{kcal} / 24 \mathrm{~h}$, and the LOA were $-721 \mathrm{kcal} / 24 \mathrm{~h}$ and $1,124 \mathrm{kcal} / 24 \mathrm{~h}$ (fig. 3). 


\section{Discussion}

The study was conducted to assess the applicability of commonly used RMR prediction equations in highly trained, heavyweight endurance athletes. In general, prediction equations significantly underestimated the RMR in male athletes, whereas no differences between measured and predicted RMR were observed in female athletes. This effect might be attributed to the remarkable size of the FFM in male elite rowers and canoeists in the present study $(81.0 \pm 8.0 \mathrm{~kg}$ FFM and $12.7 \pm 2.0 \%$ body fat for males and $56.1 \pm 7.0 \mathrm{~kg}$ FFM and $18.5 \pm$ $4.0 \%$ body fat for females). The observed total body weight of $92.9 \pm 10 \mathrm{~kg}$ and average FFM of $81.0 \pm 8 \mathrm{~kg}$ in male participants is much higher than FFM reported in other RMR measurement studies where the mean FFM typically ranges from 38 to $62 \mathrm{~kg}$ in sedentary or moderately active individuals $[26,35,36]$. In contrast, both the total body weight and the FFM in female athletes were not obviously higher compared to values in the literature. As previously shown, the prediction error is higher when the FFM is either decreased or elevated. Mueller et al. [35] reported that commonly used RMR prediction equations are biased in both obese and underweight subjects, with underestimation at high RMR and overestimation at low RMR. Therefore, RMR equations used to predict the RMR in athletes should consider anthropometric differences between the general population and athletes.

A bias ranging from $133 \mathrm{kcal} / 24 \mathrm{~h}$ (CUN) to 202 $\mathrm{kcal} / 24 \mathrm{~h}(\mathrm{HB})$ was observed when the RMR was predicted in athletes. The question of what is an acceptable bias needs to be evaluated from a practical perspective and cannot be answered solely by using statistical measures [32]. An underestimation of 133-202 kcal/day seems to be negligible in theory but may be of practical importance if an athlete tries to gain weight with a combined schedule of exercise training and a fine-tuned diet sheet.

For example, if the RMR is underestimated by 200 $\mathrm{kcal} / 24 \mathrm{~h}$ as observed in $\mathrm{HB}$, the individual's energy requirement will be underestimated by approximately $360-460 \mathrm{kcal} / \mathrm{day}$ as the physical activity level (which serves to calculate total energy requirement from the RMR as RMR $\times$ physical activity level) ranges from 1.82.3 in highly trained athletes, which might be of importance during dietary counseling of the individual [11]. A daily caloric deficiency of $460 \mathrm{kcal}$ would result in a monthly body weight loss of approximately $1.5-1.8 \mathrm{~kg}$ if not corrected by an increased dietary intake, for example with an additional large cereal bowl with milk or two stuffed rolls.

However, a high but consistent bias would be a minor concern if the SD of the mean difference between the measurement and the prediction is small (i.e. a narrow range of the 95\% LOA). In this case, predictions may be adjusted by subtracting the bias [32]. Nevertheless, the LOA are high in both prediction equations, indicating that relevant over- or underestimation of the RMR may occur in the individual. In addition, the proportional bias observed in the tested prediction equations indicates that underestimation of the RMR is more likely to occur at high RMR. Results of the present study indicate an obvious proportional bias with underestimation of the RMR in athletes with a high RMR and overestimation of the RMR in athletes with a low RMR. However, a proportional bias in Bland-Altman plots may also be an artifact of the plotting procedure, and regression analysis is needed to identify a proportional bias [34]. When performing a regression analysis, the slope for both prediction equations tested against calorimetry is not close to 1 and the intercept is not close to zero, indicating that the proportional bias observed in athletes is veritable.

As FFM accounts for up to $80 \%$ of the RMR $[1,5]$ it may be suggested that underestimation occurs in individuals with a high FFM and low body fat content. This may also explain why in males $(12.7 \pm 2.0 \%$ body fat $)$ prediction equations underestimated the RMR while in females $(18.5 \pm 4.0 \%$ body fat) no statistical significant difference between measured and predicted RMR was observed. It may be concluded that in athletes with a low body fat percentage the RMR may be significantly underestimated when using CUN or $\mathrm{HB}$ to estimate the RMR.

However, it needs to be emphasized that the athletic population presented in this study consisted of elite rowing and canoeing athletes of the German national teams with a large body size and FFM. In other athletic populations where the body size and FFM do not differ from those of the general population, differences in predicted and measured RMR might be negligible in the daily routine of sports nutrition.

\section{Conclusion}

The predicted RMR in heavyweight endurance athletes are significantly biased by approximately 150-200 $\mathrm{kcal} / 24 \mathrm{~h}$ when standard equations suggested by the 
ACSM are used [11]. The mean difference between measured and predicted RMR was higher at high values of measurement, indicating that underestimation of the RMR is more likely to occur at high RMR. In athletes with a high FFM, prediction equations might therefore not be applicable to estimate energy requirements. Instead, measurement of the resting energy expenditure might be needed in the individual heavyweight athlete.

\section{References}

1 Speakman JR, Selman C: Physical activity and resting metabolic rate. Proc Nutr Soc 2003;62:621-634

2 Wang Z, Heshka S, Zhang K, Boozer CN, Heymsfield SB: Resting energy expenditure: systematic organization and critique of prediction methods. Obes Res 2001;9:331-336.

3 Korth O, Bosy-Westphal A, Zschoche P, Gluer CC, Heller M, Muller MJ: Influence of methods used in body composition analysis on the prediction of resting energy expenditure. Eur J Clin Nutr 2007;61:582-589.

4 FAO/WHO/UNU Expert Consultation: Human energy requirements: scientific background papers from the Joint $\mathrm{FAO} / \mathrm{WHO} /$ UNU Expert Consultation, October 17-24, 2001, Rome, Italy. Food Nutr Tech Rep Ser 2005, pp 35ff.

5 Bader N, Bosy-Westphal A, Dilba B, Muller MJ: Intra- and interindividual variability of resting energy expenditure in healthy male subjects - biological and methodological variability of resting energy expenditure. $\mathrm{Br}$ J Nutr 2005;94:843-849.

6 Weyer C, Walford RL, Harper IT, Milner M, MacCallum T, Tataranni PA, Ravussin E: Energy metabolism after 2 years of energy restriction: the biosphere 2 experiment. Am J Clin Nutr 2000;72:946-953.

7 Illner K, Brinkmann G, Heller M, BosyWestphal A, Muller MJ: Metabolically active components of fat free mass and resting energy expenditure in nonobese adults. Am J Physiol Endocrinol Metab 2000;278:E308E315.

8 Tremblay A, Coveney S, Despres JP, Nadeau A, Prud'homme D: Increased resting metabolic rate and lipid oxidation in exercisetrained individuals: evidence for a role of beta-adrenergic stimulation. Can J Physiol Pharmacol 1992;70:1342-1347.

9 Cunningham JJ: A reanalysis of the factors influencing basal metabolic rate in normal adults. Am J Clin Nutr 1980;33:2372-2374.

10 Harris JA, Benedict FA: A Biometric Study of Basal Metabolic Rate in Man. Washington, Carnegie Institute of Washington, 1919.

11 Rodriguez NR, DiMarco NM, Langley S: Position of the American Dietetic Association, Dietitians of Canada, and the American College of Sports Medicine: nutrition and athletic performance. J Am Diet Assoc 2009; 109:509-527.

12 Thompson J, Manore MM: Predicted and measured resting metabolic rate of male and female endurance athletes. J Am Diet Assoc 1996;96:30-34.
13 Malina RM: Body composition in athletes: assessment and estimated fatness. Clin Sports Med 2007;26:37-68.

14 Kerr DA, Ross WD, Norton K, Hume P, Kagawa M, Ackland TR: Olympic lightweight and open-class rowers possess distinctive physical and proportionality characteristics. J Sports Sci 2007;25:43-53.

15 Harris JA, Benedict FG: A biometric study of human basal metabolism. Proc Natl Acad Sci USA 1918;4:370-373.

16 De Lorenzo A, Bertini I, Candeloro N, Piccinelli R, Innocente I, Brancati A: A new predictive equation to calculate resting metabolic rate in athletes. J Sports Med Phys Fitness 1999;39:213-219.

17 al-Adsani H, Hoffer LJ, Silva JE: Resting energy expenditure is sensitive to small dose changes in patients on chronic thyroid hormone replacement. J Clin Endocrinol Metab 1997;82:1118-1125.

18 Horner NK, Lampe JW, Patterson RE, Neuhouser ML, Beresford SA, Prentice RL: Indirect calorimetry protocol development for measuring resting metabolic rate as a component of total energy expenditure in freeliving postmenopausal women. J Nutr 2001; 131:2215-2218.

19 Platte P, Wurmser H, Wade SE, Mercheril A, Pirke KM: Resting metabolic rate and dietinduced thermogenesis in restrained and unrestrained eaters. Int J Eat Disord 1996;20 33-41.

20 Thompson JL, Manore MM, Skinner JS, Ravussin E, Spraul M: Daily energy expenditure in male endurance athletes with differing energy intakes. Med Sci Sports Exerc 1995;27:347-354.

21 Van Zant RS: Influence of diet and exercise on energy expenditure - a review. Int J Sport Nutr 1992;2:1-19.

22 Sjodin AM, Forslund AH, Westerterp KR Andersson AB, Forslund JM, Hambraeus LM: The influence of physical activity on BMR. Med Sci Sports Exerc 1996;28:85-91.

23 Scharhag-Rosenberger F, Carlsohn A, Cassel M, Mayer F, Scharhag J: How to test maximal oxygen uptake: a study on timing and testing procedure of a supramaximal verification test. Appl Physiol Nutr Metab 2011;36:153160.

24 Plasqui G, Kester AD, Westerterp KR: Seasonal variation in sleeping metabolic rate, thyroid activity, and leptin. Am J Physiol Endocrinol Metab 2003;285:E338-E343.
25 Parizkova J, Buzkova P: Relationship between skinfold thickness measured by Harpenden caliper and densitometric analysis of total body fat in men. Hum Biol 1971;43:16-21.

26 Weststrate JA: Resting metabolic rate and diet-induced thermogenesis: a methodological reappraisal. Am J Clin Nutr 1993;58:592601.

27 Compher C, Frankenfield D, Keim N, RothYousey L: Best practice methods to apply to measurement of resting metabolic rate in adults: a systematic review. J Am Diet Assoc 2006;106:881-903.

28 Hoffman JR, Kang J, Ratamess NA, Jennings PF, Mangine G, Faigenbaum AD: Thermogenic effect from nutritionally enriched coffee consumption. J Int Soc Sports Nutr 2006; 3:35-41.

29 Tremblay A, Nadeau A, Fournier G, Bouchard C: Effect of a three-day interruption of exercise-training on resting metabolic rate and glucose-induced thermogenesis in training individuals. Int J Obes 1988;12:163168.

30 Rodriguez G, Moreno LA, Sarria A, Fleta J, Bueno M: Resting energy expenditure in children and adolescents: agreement between calorimetry and prediction equations. Clin Nutr 2002;21:255-260.

31 Weir JB: New methods for calculating metabolic rate with special reference to protein metabolism. J Physiol 1949;109:1-9.

32 Bland JM, Altman DG: Measuring agreement in method comparison studies. Stat Methods Med Res 1999;8:135-160.

33 Bland JM, Altman DG: Comparing methods of measurement: why plotting difference against standard method is misleading. Lancet 1995;346:1085-1087.

34 Hopkins WG: Bias in Bland-Altman but not Regression Validity Analysis. Sportscience 2004;8:42-46.

35 Muller MJ, Bosy-Westphal A, Klaus S, Kreymann G, Luhrmann PM, Neuhauser-Berthold M, Noack R, Pirke KM, Platte P, Selberg $\mathrm{O}$, Steiniger J: World Health Organization equations have shortcomings for predicting resting energy expenditure in persons from a modern, affluent population: generation of a new reference standard from a retrospective analysis of a German database of resting energy expenditure. Am J Clin Nutr 2004;80:1379-1390.

36 Henry CJ, Lightowler HJ, Marchini J: Intraindividual variation in resting metabolic rate during the menstrual cycle. Br J Nutr 2003; 89:811-817. 